\title{
MIR205HG acts as a ceRNA to expedite cell proliferation and progression in lung squamous cell carcinoma via targeting miR- 299-3p/MAP3K2 axis
}

Limin Liu', Yulei Li ${ }^{1}$, Ruifang Zhang ${ }^{1}$, Chun $\mathrm{Li}^{1}$, Jing Xiong ${ }^{1}$ and Yuan $\mathrm{Wei}^{2^{*}}$

\begin{abstract}
Introduction: Long noncoding RNAs (IncRNAs) have been associated with many types of cancers, but their molecular mechanisms in lung squamous cell carcinoma (LUSC) have not been fully studied. Therefore, the current study investigated the regulation role of microRNA-205 host gene (MIR205HG) in LUSC and recognized the target genes managed by this IncRNA.

Methods: MIR205HG expression was assessed by the quantitative real-time polymerase chain reaction (qRT-PCR) analysis. The effects of silenced MIR205HG on cell biological behaviors were detected by colony formation assay, transwell assay, flow cytometry analysis and western blot analysis. Luciferase reporter assay and RNA immunoprecipitation (RIP) assay were utilized to proof the binding relationship between miR-299-3p and MIR205HG/mitogen-activated protein kinase kinase kinase 2 (MAP 3 K2).

Results: The expression levels of MIR205HG in LUSC tissues and cell lines were obviously up-regulated. Downregulation of MIR205HG expression remarkably reduced cell proliferation, migration and epithelial-to-mesenchymal transition (EMT) progression, whereas promoted cell apoptosis. MIR205HG could bind with miR-299-3p and downregulation of MIR205HG elevated miR-299-3p expression. MAP 3 K2 acted as the target gene of miR-299-3p and was up-regulated by MIR205HG overexpression. Overexpressing MAP $3 \mathrm{~K} 2$ could counteract the effects of downregulating MIR205HG on LUSC progression to some degree.
\end{abstract}

Conclusion: MIR205HG acts as a competing endogenous RNA (ceRNA) to expedite cell proliferation and progression via targeting miR-299-3p in LUSC.

Keywords: Lung squamous cell carcinoma, MIR205HG, miR-299-3p, Competing endogenous RNA (ceRNA), MAP 3 K2

\section{Introduction}

Lung cancer maintains a serious common reason of tumor-related deaths in developed nations [1]. About $78 \%$ of lung cancers belong to the category of nonsmall cell lung cancer (NSCLC). Further, NSCLC is

\footnotetext{
* Correspondence: touyuangeng695@163.com

${ }^{2}$ Three Wards of Outpatient Service, Wuhan Jin Yin Tan Hospital, No.1 Yintan Road, Dongxihu District, Wuhan 433013, Hubei, China

Full list of author information is available at the end of the article
}

pathologically divided into four groups: adenocarcinoma, squamous cell carcinoma (SCC), large cell carcinoma and neuroendocrine cancer [2]. Targeted molecular treatments have offered a number of appealing benefits to patients with adenocarcinoma [3-5]. However, these new therapies have brought not much effect in lung squamous cell carcinoma (LUSC) [6]. Thence, we need more valid treatments based on genomic methods for LUSC.

C C The Author(s). 2020 Open Access This article is licensed under a Creative Commons Attribution 4.0 International License, which permits use, sharing, adaptation, distribution and reproduction in any medium or format, as long as you give appropriate credit to the original author(s) and the source, provide a link to the Creative Commons licence, and indicate if changes were made. The images or other third party material in this article are included in the article's Creative Commons licence, unless indicated otherwise in a credit line to the material. If material is not included in the article's Creative Commons licence and your intended use is not permitted by statutory regulation or exceeds the permitted use, you will need to obtain permission directly from the copyright holder. To view a copy of this licence, visit http://creativecommons.org/licenses/by/4.0/. The Creative Commons Public Domain Dedication waiver (http://creativecommons.org/publicdomain/zero/1.0/) applies to the data made available in this article, unless otherwise stated in a credit line to the data. 
Plenty of studies have revealed that long noncoding RNAs (lncRNAs) may serve as crucial cis- or transregulators in multiple biological behaviors [2, 7]. Mutation and modulation of lncRNA expression will influence a large number of diseases. MicroRNA-205 host gene (MIR205HG) has been proofed to accelerate cell growth in Head and Neck Squamous Cell Carcinoma (HNSCC) by down-regulating miR-590-3p [8]. Nevertheless, studies on the function of MIR205HG in the progression of LUSC are still blank, so its biological functions are needed to be featured.

Recently, according to findings on a wide range of non-coding RNAs, microRNAs (miRNAs) are small non-coding RNAs participating in the suppression or down-regulation of target gene transcription in the way of sequence-dependent $[1,2]$. The capacity of miRNAs is particular. A miRNA can control a great deal of protein-coding RNAs of human cells $[9,10]$. Thence, regulating RNA networks may be interfered by the aberrant expression of miRNAs [11, 12], which is conducive to tumorigenesis, tumor metastasis and drug resistance $[3,4]$. As a matter of fact, aberrantly expressed miRNAs have been studied in different cancers, including lung SCC $[5,13]$. For instance, the expression levels of miR133a were shown dramatically low in prostate cancer tissues compared with adjacent normal tissues [14]. MiR-299-3p has been explored to express aberrantly in certain types of cancers, such as colon carcinoma and lung cancer [15-17]. The exact role and functional mechanism of miR-299-3p in LUSC maintain uncovered. Thence, this study was designed to explore the molecular mechanism of relationship between MIR205HG and miR-299-3p in LUSC.

\section{Methods}

\section{Cell culture}

Human normal lung epithelial cell (BEAS-2B) and lung cancer cells (NCI-H520, SK-MES-1, NCI-H1703) were all bought from Chinese Academy of Sciences (Beijing, China). The above cells were inoculated in RPMI-1640 medium (Invitrogen, Carlsbad, CA, USA) adding 10\% FBS (Invitrogen), then mixed with 1\% penicillin/streptomycin (Sigma-Aldrich, Milan, Italy) and cultivated in a $5 \% \mathrm{CO}_{2}$ incubator at $37^{\circ} \mathrm{C}$. medium for incubation was required to change every 3 days.

\section{Cell transfection}

Cells were put into a fresh 6-well plate until cells were passaged at $80 \%$ confluence. NCI-H520 and SK-MES-1 cells were co-transfected with shRNAs targeting MIR205HG (sh-MIR205HG\#1/\#2) and sh-NC. The pcDNA3.1/MIR205HG, pcDNA3.1/MAP $3 \mathrm{~K} 2$ and the empty pcDNA3.1 were constructed by Genechem (Shanghai China). The miR-299-3p mimics and NC- mimics were also gained from Genechem. All transfections were conducted by Lipofectamine 2000 (Invitrogen).

\section{Quantitative real-time polymerase chain reaction (qRT- PCR) analysis}

Total RNAs of cells were extracted by TRIzol reagent which was purchased from Invitrogen. The total RNAs were reverse-transcribed into cDNA under a Reverse Transcription Kit (Invitrogen). qRT-PCR analysis was achieved using SYBR Green Premix PCR Master Mix (Roche, Mannheim, Germany) under ABI HT9600 (Applied Biosystems, Foster City, CA, USA). The fold expression changes were calculated by using $2^{-\Delta \Delta C t}$ method, and GAPDH/U6 was seen as the endogenous control.

\section{Colony formation assay}

SK-MES-1 and NCI-H520 cells were plated into 6-well plates and cultured after transfection. After 14 days, cells were cleaned with PBS (Sigma-Aldrich) and fixed in paraformaldehyde (Sigma-Aldrich) for $10 \mathrm{~min}$, dyed by crystal violet (Sigma-Aldrich) for $5 \mathrm{~min}$. Finally, the visible colony numbers were calculated manually.

\section{Transwell migration assay}

Serum-free medium containing SK-MES-1 and NCIH520 cells was placed in the top compartment and the lower compartment was filled with 10\% FBS (Sigma-Aldrich). Matrigel (Corning Incorporated, NY, USA) was additionally pre-coated on the apical compartment for migration assay. After cultivating for $48 \mathrm{~h}$, the bottom of the chamber was fixed by methanol (Sigma-Aldrich), and then dyed with crystal violet (Sigma-Aldrich). The cells that had migrated were counted at 5 randomly chosen visual fields using an inverted microscope (Olympus, Tokyo, Japan).

\section{Western blot analysis}

When reached to $80-90 \%$ confluent, cells were collected for total protein extraction by using RIPA cell lysis. After the concentration measured via a Pierce Bicinchoninic acid (BCA) Protein detection kit (Bio-Rad Laboratories, Hercules, CA, USA), proteins were isolated by performing SDS-PAGE and then moved onto a PVDF membrane (Beyotime, Shanghai, China). The membrane was sealed with $5 \%$ fat-free milk and rinsed by Tris-buffered saline/ Tween 20 (TBST), followed by overnight incubation with the primary antibodies at $4{ }^{\circ} \mathrm{C}$. The primary antibodies used in this study were as below: anti-E-cadherin (ab194982, Abcam), anti-N-cadherin (ab202030, Abcam), anti-Vimentin (ab193555, Abcam), anti-MAP 3 K2 (ab33918, Abcam) and antiGAPDH (ab8245, Abcam). Following washing in TBST, the membranes 
were subjected to $2 \mathrm{~h}$ of incubation with secondary antibodies at room temperature. The, the blots were visualized by the application of enhanced chemiluminescence (ECL; Amersham Pharmacia Biotec, Buckinghamshire, UK). GAPDH served as the internal control. The experiment was conducted in triplicate.

\section{Apoptosis analysis}

Cell apoptosis was examined at $48 \mathrm{~h}$ after transfection using FITC Annexin V/PI Apoptosis Detection Kit I (Ribobio, Guangzhou, China). In short, cells were reaped and cleaned in PBS (Sigma-Aldrich) and resuspended in $70 \%$ cooled ethanol (Sigma-Aldrich). The apoptosis ratio was determined by using FlowJo software (Ashland, OR, USA).

\section{RNA immunoprecipitation (RIP) assay}

RIP experiments were performed using the Magna RNA-Binding Protein Immunoprecipitation Kit (Millipore, MA, USA). Then, cell lysates were cultivated with RIP buffer containing magnetic beads conjugated with human anti-Ago2 (ab32381, Abcam) or anti-IgG (Millipore, MA, USA). Furthermore, qRT-PCR was performed to evaluate the expression levels of MIR205HG, miR-299-3p and MAP 3 K2. Normal IgG was considered as control.

\section{Luciferase reporter assay}

The wild-type and mutant binding sites of MIR205HG or MAP 3 K2 to miR-209-3p were sub-cloned into pmirGLO dual-luciferase vector to construct plasmids and then co-transfected with miR-299-3p mimics and pcDNA3.1/MIR205HG into NCI-H520 or SK-MES-1 cells, separately. Dual-luciferase reporter system was applied for detecting the activity of luciferase.

\section{Statistical analysis}

Data analysis was performed using GraphPad Prism 7 software package (La Jolla, CA, USA). Data came from at least three independent assays were showed as mean \pm standard deviation (SD). ANOVA analysis and Student's t-test were employed for evaluating difference of 2 or more groups. $P<0.05$ had statistical significance.

\section{Results}

Cutting down MIR205HG expression impairs cell proliferation and migration abilities in LUSC

MicroRNA-205 host gene (MIR205HG) has been proofed to accelerate cell growth in HNSCC by downregulating miR-590-3p [8]. Here in the first place, we applied GEPIA dataset to examine expression of MIR205HG in LUSC tissues. The results depicted that MIR205HG was significantly up-regulated in LUSC tissues compared with the adjacent normal tissues (Fig. 1a).
Then, qRT-PCR detected that MIR205HG expression was relatively high in LUSC cell lines (NCI-H520, SKMES-1 and NCI-H1703) compared with the normal control (Fig. 1b). Besides, NCI-H520 and SK-MES-1 cells were singled out for the forthcoming experiment for that they the higher level of MIR205HG.

Then, two shRNAs targeting MIR205HG were transfected into NCI-H520 and SK-MES-1 cells to detect the efficiency of down-regulating MIR205HG. Consequently, as depicted in Fig. 1c, the expression level of MIR205HG in selected cell lines were decreased conspicuously. Functionally, number of colonies declined distinctly in response to MIR205HG down-regulation (Fig. 1d). On the contrary, cell apoptosis ability was enhanced obviously, as demonstrated in Fig. 1e. In parallel, transwell assay showed that migration abilities of both cell lines were impaired observably (Fig. 1f). Moreover, from the results of western blot analysis, the expression of the epithelial marker (E-cadherin) was elevated observably while that of the mesenchymal markers $(\mathrm{N}$-cadherin and Vimentin) was reduced comparably (Fig. 1g, Supplementary Figure 1A and Supplementary information file 1A). The above findings illustrated that MIR205HG had tumor-promoting function in LUSC.

\section{MIR205HG is an upstream factor for miR-299-3p in LUSC}

We obtained potential miRNAs which had binding sites with MIR205HG via starBase database. Then through searching out the expression level of candidate miRNAs in LUSC from dbDEMC 2 website, 3 miRNAs (miR-2993p, miR-143-3p and miR-122-5p) with low expression were selected out (Fig. 2a). RIP assay was applied to verify the binding situations between 3 miRNAs and MIR205HG. As denoted in Fig. 2b, only miR-299-3p and MIR205HG were significantly enriched in Ago2 precipitated RNA-induced silencing complexes (RISCs), indicating that miR-299-3p and MIR205HG involved in ceRNA axis. It further bolted miR-299-3p as our target miRNA. Figure 2c depicted the binding sites between miR-299-3p and wild type MIR205HG (MIR205HGWT)/mutant MIR205HG (MIR205HG-Mut). Luciferase reporter assay exhibited that the luciferase activity of MIR205HG-WT obviously declined by elevated miR299-3p overexpression, whereas that of MIR205HG-Mut bore little alteration (Fig. 2d). Besides, the expression of miR-299-3p was up-regulated dramatically under the condition of depleting MIR205HG in both cell lines (Fig. $2 e)$. Hence, we concluded that miR-299-3p was the downstream molecule of MIR205HG in LUSC.

MAP $3 \mathrm{~K} 2$ is the target gene of miR-299-3p and indirectly regulated by MIR205HG

To forecast the possible target of miR-299-3p, we acquired the common target genes from 3 databases, 


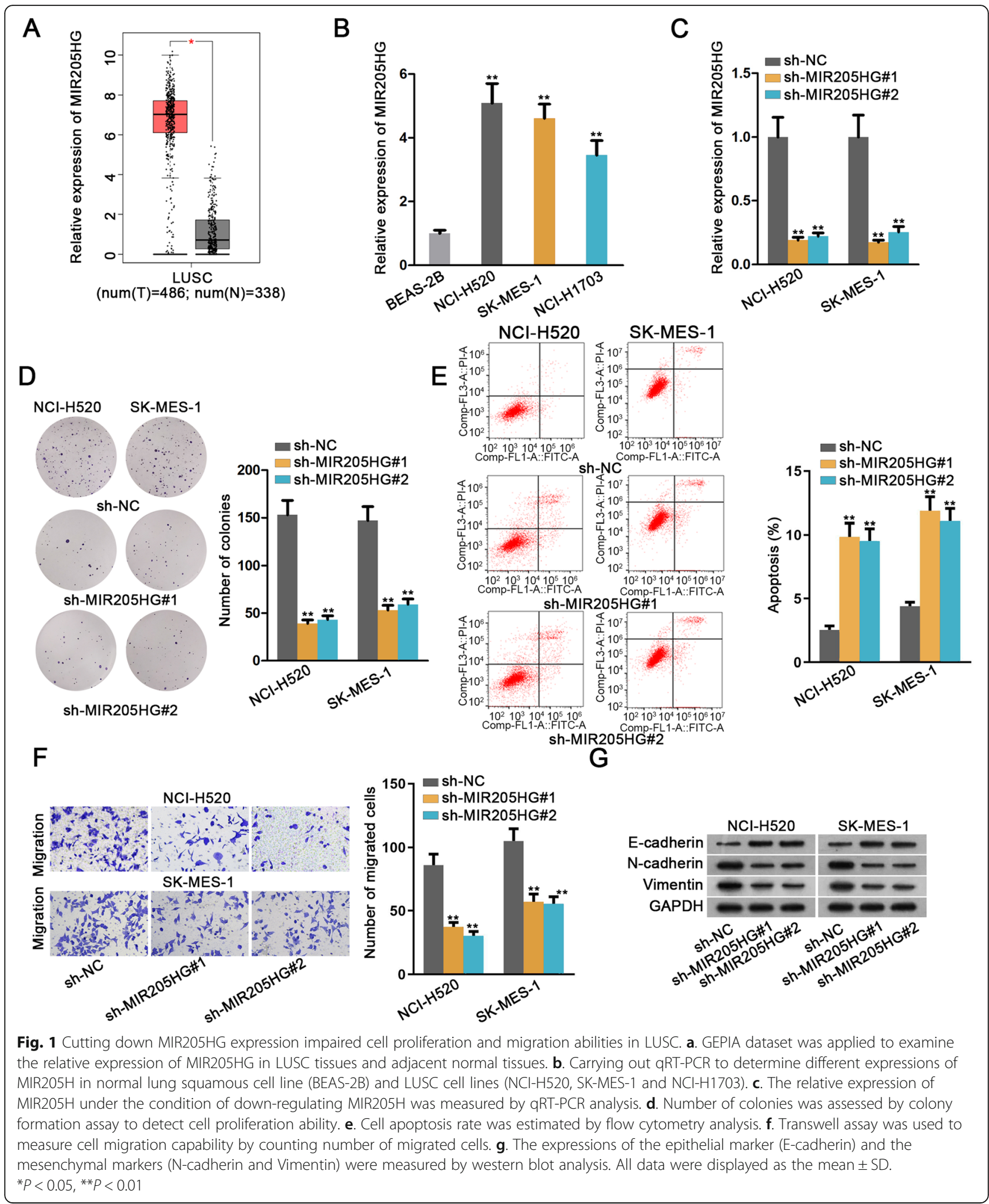

including RNA22, miRmap and miRanda (Fig. 3a). There were seven candidate target genes of miR-299-3p (Fig. $3 \mathrm{~b})$. Previous studies have reported that MAP $3 \mathrm{~K} 2$ acted as an oncogene in the progression of certain types of cancer $[18,19]$. Thus, MAP $3 \mathrm{~K} 2$ was chosen as the target gene of miR-299-3p. Simultaneously, miR-299-3p and MAP $3 \mathrm{~K} 2$ had binding sites, which were displayed in Fig. 3c. Luciferase reporter assay was used to further 


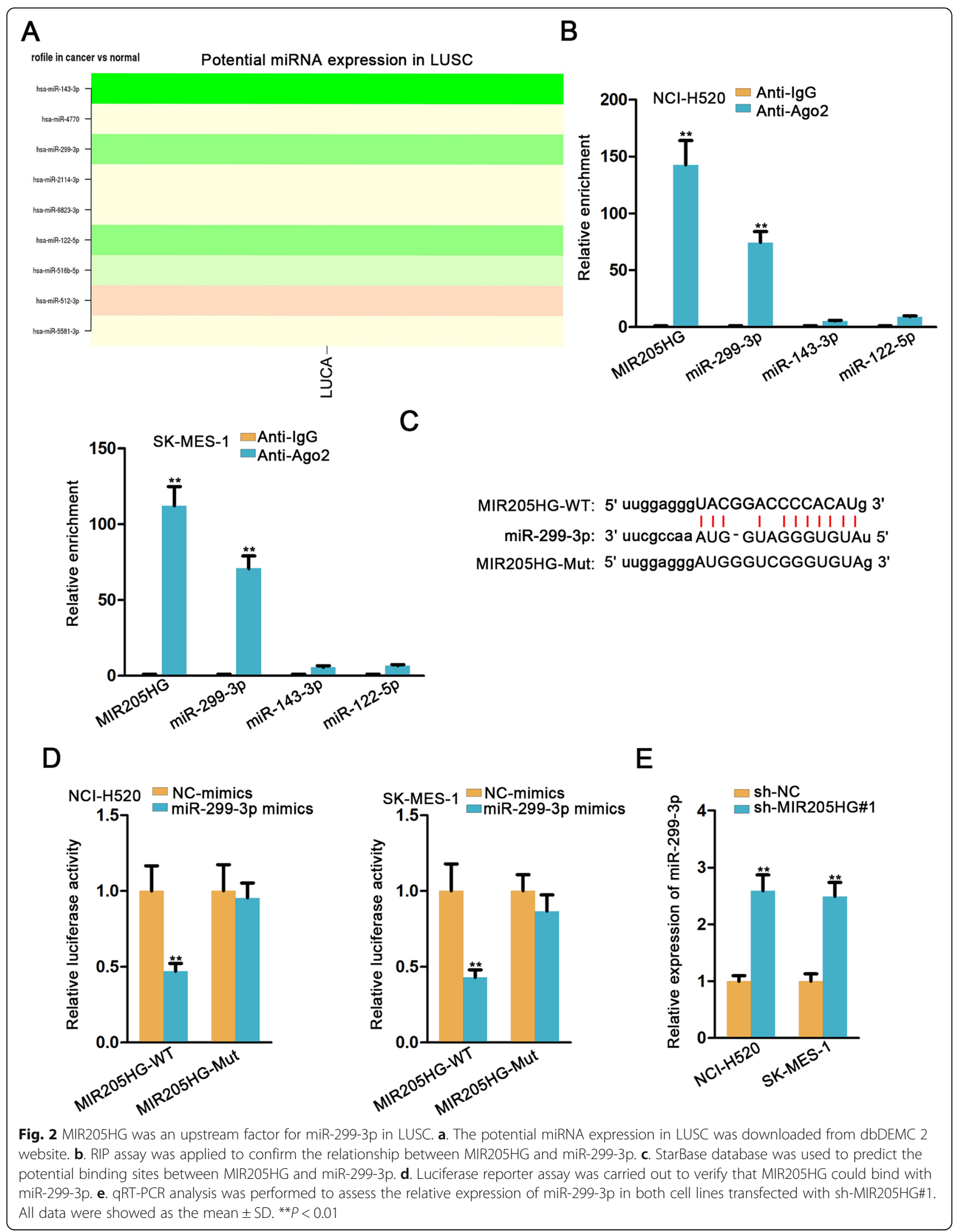


prove binding relationship between miR-299-3p and MAP 3 K2. As illustrated in Fig. 3d, miR-299-3p overexpression decreased the luciferase activity of MAP $3 \mathrm{~K} 2-$ WT group via binding to MAP $3 \mathrm{~K} 2-\mathrm{WT}$, while the luciferase activity of mutant MAP 3 K2 (MAP 3 K2-Mut) group had no alteration. Similarly, RIP assay showed that MIR205HG, miR-299-3p and MAP 3 K2 were all enriched in Ago2 containing beads in both cell lines (Fig. 3e). Via western blot analysis, the expression level of MAP $3 \mathrm{~K} 2$ was decreased with the down-regulation of MIR205HG, then increased with the overexpression of MAP $3 \mathrm{~K} 2$ (Fig. 3f, Supplementary Figure 1B and Supplementary information file 1B). To draw a

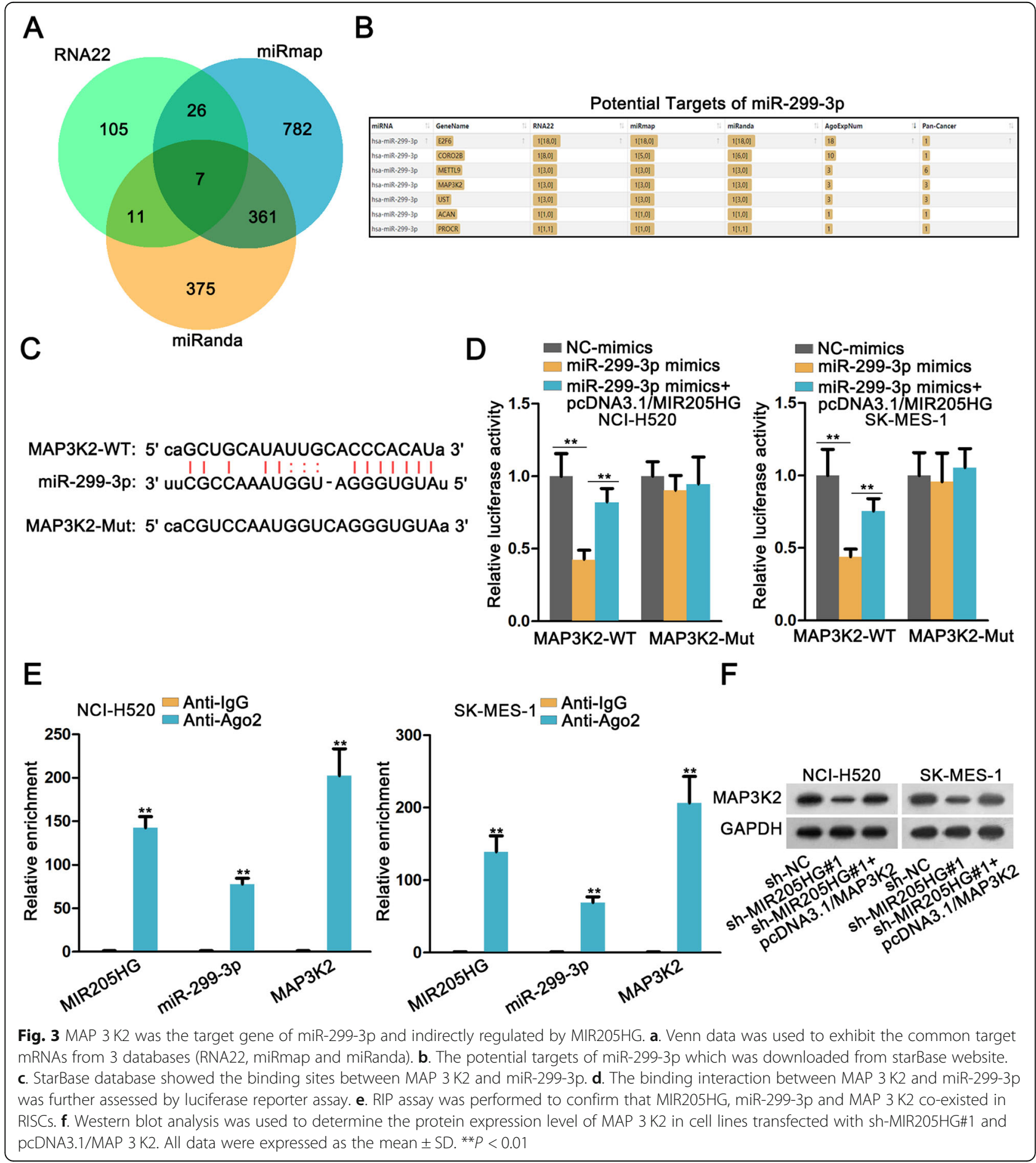




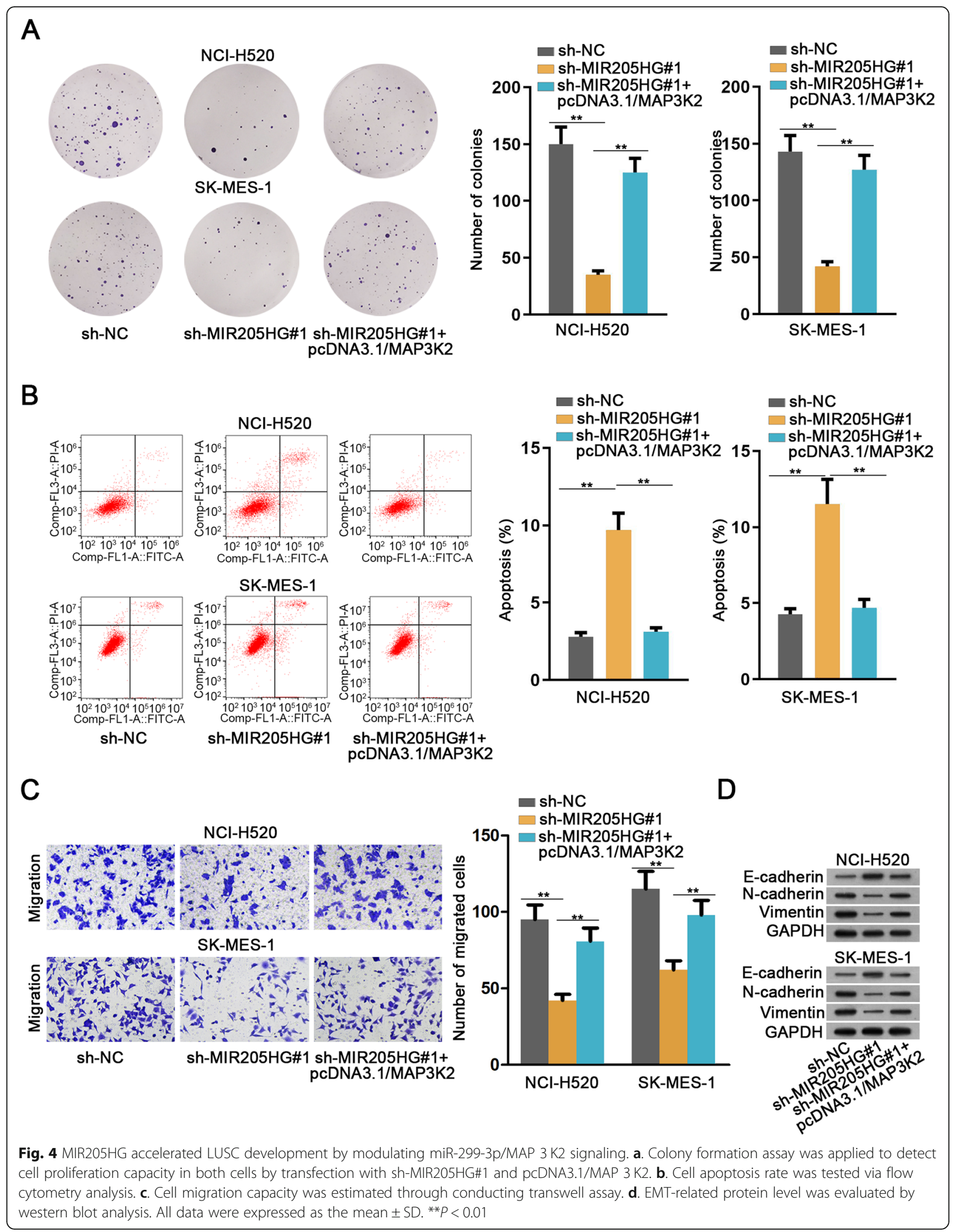


conclusion, MAP $3 \mathrm{~K} 2$ acted as the target gene of miR299-3p and indirectly regulated by MIR205HG.

\section{MIR205HG accelerates LUSC development by regulating miR-299-3p/MAP 3 K2 pathway}

We carried out rescue function assays to verify the effects of modulating relationship between MIR205HG and MAP $3 \mathrm{~K} 2$ on LUSC development. The results revealed that overexpressing MAP $3 \mathrm{~K} 2$ could restore number of colonies reduced by reducing MIR205HG (Fig. 4a). In contrast, the overexpression of MAP $3 \mathrm{~K} 2$ decreased cell apoptosis up-regulated by MIR205HG knockdown (Fig. 4b). Transwell assay also proved that elevating MAP $3 \mathrm{~K} 2$ could recover the reduced cell migration abilities caused by silenced MIR205HG (Fig. 4c). Evidence from western blot analysis suggested that overexpression of MAP $3 \mathrm{~K} 2$ decreased the expression of E-cadherin that was upregulated by MIR205HG knockdown. N-cadherin and Vimentin expressions which were decreased by MIR205HG knockdown were enhanced by overexpression of MAP $3 \mathrm{~K}$ (Fig. 4d, Supplementary Figure 1C and Supplementary information file 1C). Altogether, MIR205HG could up-regulate MAP $3 \mathrm{~K} 2$ expression by sponging miR299-3p in LUSC, thereby regulating LUSC cell proliferation, apoptosis, migration and EMT process.

\section{Discussion}

This study indicated that MIR205HG may be a crucial regulator for cell proliferation, migration and EMT progression in LUSC. First of all, we found that the expressions of MIR205HG in LUSC tissues and cell lines (NCI-H520, SK-MES-1 and NCI-H1703) were highly expressed. In addition, down-regulation of MIR205HG suppressed cell proliferation, migration and EMT process, whereas enhanced cell apoptosis. Besides, the results also revealed that reducing MIR205HG increased the expression level of miR-299-3p. It further proved that MIR205HG was an upstream factor for miR-299-3p. On the other hand, MAP $3 \mathrm{~K} 2$ acted as the target gene of miR-299-3p, which was regulated by MIR205HG indirectly. Increasing MAP $3 \mathrm{~K} 2$ expression could restore the effects caused by inhibiting MIR205HG on cell biological functions. To sum up, MIR205HG could regulate MAP 3 K2 expression via miR-299-3p to promote the progression of LUSC. Furthermore, evidence of MIR205HG functionality in LUSC might extend to clinical pathologic features of LUSC patients. This study may have some referential meaning for the development of possible therapeutics against LUSC.

It is well-acknowledged that lncRNAs have multiple molecular functions, including adjusting transcriptional forms and protein activities and altering RNA processes $[20,21]$. However, it is still not clear whether these lncRNAs are the causes or symptoms of morbid state. A vast number of studies have indicated that many disordered lncRNAs existed in all types of human diseases, including cancers [22, 23]. This research demonstrated the high expression of MIR205HG in LUSC tissues and cell lines. Depletion of MIR205HG repressed cellular activities in LUSC, suggesting that MIR205HG worked as an oncogene in LUSC.

Generally, miRNAs play a role in cancer cells by means of promoting degradation of the targeted genes $[24,25]$. ABCE1 is the target gene of miR-299-3p in lung cancer cells [16]. In human colon carcinoma, miR-2993 p suppresses the tumor process in the way of immediately targeting VEGFA [15]. Then we intended to probe a new target of miR-299-3p in LUSC cells. In this study, MAP $3 \mathrm{~K} 2$ was identified as the target mRNA of miR299-3p. Overexpressing MIR205HG could cut down miR-299-3p expression through binding with it. In the same time, MIR205HG enhanced MAP 3 K2 expression via sequestering miR-299-3p.

Previous papers found out that MAP 3 K2 could distinguish tumor cells from non-tumor normal cells [18]. Furthermore, MAP $3 \mathrm{~K} 2$ contributes to the growth and migration of liver cancer cells [24, 25]. MiR-520b targeting MAP $3 \mathrm{~K} 2$ could impair hepatoma cell proliferation ability [19]. These findings all revealed that MAP $3 \mathrm{~K} 2$ probably play a significant role in the development of liver cancer. Similarly, MAP $3 \mathrm{~K} 2$ in this research was proved to exert tumor-promoting effects in LUSC. In rescue function assays, up-regulating MAP $3 \mathrm{~K} 2$ expression recovered cell proliferation and migration abilities and EMT process, which were impaired by depleting MIR205HG.

\section{Conclusions}

MIR205HG up-regulates MAP 3 K2 expression via sponging miR-299-3p to facilitate cell proliferation, migration and EMT process in LUSC.

\section{Supplementary information}

Supplementary information accompanies this paper at https://doi.org/10. 1186/s12890-020-1174-2.

Additional file 1: Figure S1. A. Another two data obtained from two repeated western blot analyses for Fig. 1g. B. Another two data obtained from two repeated western blot analyses for Fig. 3f. C. Another two data obtained from two repeated western blot analyses for Fig. 4d.

Additional file 2. A. The original western blot data for corresponding cropped data in Fig. 1g and Supplementary Fig. 1A. B. The original western blot data for corresponding cropped data in Fig. $3 f$ and Supplementary Fig. 1B. C. The original western blot data for corresponding cropped data in Fig. 4d and Supplementary Fig. 1C.

\section{Abbreviations}

LUSC: Lung squamous cell carcinogenesis; IncRNA: Long non-coding RNA; EMT: Epithelial-to-mesenchymal transition; ceRNA: Competing endogenous RNA; NSCLC: Non-small cell lung cancer; SCC: Squamous cell carcinoma; MIR205HG: microRNA-205 host gene; HNSCC: Head and neck squamous cell 
carcinoma; miRNA: microRNA; mRNA: Messenger RNA; WT: Wild type; Mut: Mutant; RIP: RNA immunoprecipitation; MAP 3 K2: Mitogen-activated protein kinase kinase kinase 2; GRT-PCR: Quantitative real-time polymerase chain reaction; NC: Negative control; cDNA: Complementary DNA; PBS: Phosphate buffer saline; FBS: Fetal bovine serum; SDS-PAGE: Sodium dodecylsulphate polyacrylamide gel electrophoresis; PVDF: Polyvinylidene fluoride; SD: Standard deviation; ANOVA: Analysis of variance; RISC: RNA induced silence complex; ABCE1: ATP binding cassette subfamily E member 1; VEGFA: Vascular endothelial growth factor A

\section{Acknowledgements}

We are hugely grateful to everyone who participated in the experiment.

\section{Availability of data and material}

All data generated or analyzed during the current study are available from the corresponding author on reasonable request.

\section{Authors' contributions}

LL designed this study. LL and YW conducted experiments and data interpretation. $\mathrm{YL}, \mathrm{RZ}, \mathrm{CL}$ and JX were responsible for data record and investigation. All authors read and approved the final manuscript.

\section{Funding}

None.

\section{Ethics approval and consent to participate}

Not applicable.

\section{Consent for publication}

Not applicable.

\section{Competing interests}

The authors ensure that there are no competing interests in this work.

\section{Author details}

${ }^{1}$ Respiration Department, Tianyou Hospital Affiliated to Wuhan University of Science and Technology, No.9, Tujialing, Wuchang District, Wuhan 430064, Hubei, China. ${ }^{2}$ Three Wards of Outpatient Service, Wuhan Jin Yin Tan Hospital, No.1 Yintan Road, Dongxihu District, Wuhan 433013, Hubei, China.

\section{Received: 16 October 2019 Accepted: 29 April 2020}

Published online: 08 June 2020

\section{References}

1. Bartel DP. MicroRNAs: genomics, biogenesis, mechanism, and function. Cell. 2004;116(2):281-97.

2. Filipowicz W, Bhattacharyya SN, Sonenberg N. Mechanisms of posttranscriptional regulation by microRNAs: are the answers in sight? Nat Rev Genet. 2008;9(2):102-14.

3. Iorio MV, Croce CM. MicroRNAs in cancer: small molecules with a huge impact. J Clin Oncol. 2009:27(34):5848-56.

4. Rolfo C, Fanale D, Hong DS, Tsimberidou AM, Piha-Paul SA, Pauwels P, Van Meerbeeck JP, Caruso S, Bazan V, Cicero G, et al. Impact of microRNAs in resistance to chemotherapy and novel targeted agents in non-small cell lung cancer. Curr Pharm Biotechnol. 2014;15(5):475-85.

5. Yanaihara N, Caplen N, Bowman E, Seike M, Kumamoto K, Yi M, Stephens RM, Okamoto A, Yokota J, Tanaka T, et al. Unique microRNA molecular profiles in lung cancer diagnosis and prognosis. Cancer Cell. 2006;9(3):189-98.

6. Raponi M, Dossey L, Jatkoe T, Wu X, Chen G, Fan H, Beer DG. MicroRNA classifiers for predicting prognosis of squamous cell lung cancer. Cancer Res. 2009;69(14):5776-83.

7. Campos El, Reinberg D. Histones: annotating chromatin. Annu Rev Genet. 2009;43:559-99.

8. Di Agostino S, Valenti F, Sacconi A, Fontemaggi G, Pallocca M, Pulito C, Ganci F, Muti P, Strano S, Blandino G. Long non-coding MIR205HG depletes Hsa-miR-590-3p leading to unrestrained proliferation in head and neck squamous cell carcinoma. Theranostics. 2018;8(7):1850-68.

9. Qu Y, Zhang Y, Wang K, Song C, Wang P, Ye H, Zhang J, Dai L. Single Nucleotide Polymorphisms in MicroRNA-Binding Site of Epidermal Growth
Factor Receptor Signaling Pathway and Susceptibility to Esophageal Squamous Cell Carcinoma. Digest Dis (Basel, Switzerland). 2019:38(1):1-8.

10. Nam RK, Benatar T, Wallis CJD, Kobylecky E, Amemiya Y, Sherman C, Seth A. MicroRNA-139 is a predictor of prostate cancer recurrence and inhibits growth and migration of prostate cancer cells through cell cycle arrest and targeting IGF1R and AXL. Prostate. 2019;79(12):1422-38.

11. Shirmohamadi M, Eghbali E, Najjary S, Mokhtarzadeh A, Kojabad AB, Hajiasgharzadeh K, Lotfinezhad P, Baradaran B. Regulatory mechanisms of microRNAs in colorectal cancer and colorectal cancer stem cells. J Cell Physiol. 2019;235(2):776-89.

12. Butz H, Patocs A. MicroRNAs in endocrine tumors. Ejifcc. 2019:30(2):146-64

13. Moriya Y, Nohata N, Kinoshita T, Mutallip M, Okamoto T, Yoshida S, Suzuki M, Yoshino I, Seki N. Tumor suppressive microRNA-133a regulates novel molecular networks in lung squamous cell carcinoma. J Hum Genet. 2012; 57(1):38-45.

14. Tang Y, Pan J, Huang S, Peng X, Zou X, Luo Y, Ren D, Zhang X, Li R, He P, et al. Downregulation of miR-133a-3p promotes prostate cancer bone metastasis via activating PI3K/AKT signaling. J Exp Clin Cancer Res. 2018; 37(1):160.

15. Wang JY, Jiang JB, Li Y, Wang YL, Dai Y. MicroRNA-299-3p suppresses proliferation and invasion by targeting VEGFA in human colon carcinoma. Biomed Pharmacother. 2017:93:1047-54.

16. Zheng D, Dai Y, Wang S, Xing X. MicroRNA-299-3p promotes the sensibility of lung cancer to doxorubicin through directly targeting ABCE1. Int J Clin Exp Pathol. 2015;8(9):10072-81.

17. He H, Wang L, Zhou W, Zhang Z, Wang L, Xu S, Wang D, Dong J, Tang C, Tang $\mathrm{H}$, et al. MicroRNA expression profiling in clear cell renal cell carcinoma: identification and functional validation of key miRNAs. PLoS One. 2015;10(5):e0125672.

18. Cazares LH, Troyer D, Mendrinos S, Lance RA, Nyalwidhe JO, Beydoun HA, Clements MA, Drake RR, Semmes OJ. Imaging mass spectrometry of a specific fragment of mitogen-activated protein kinase/extracellular signalregulated kinase kinase kinase 2 discriminates cancer from uninvolved prostate tissue. Clin Cancer Res. 2009;15(17):5541-51.

19. Zhang W, Kong G, Zhang J, Wang T, Ye L, Zhang X. MicroRNA-520b inhibits growth of hepatoma cells by targeting MEKK2 and cyclin D1. PLoS One. 2012;7(2):e31450.

20. Wilusz JE, Sunwoo H, Spector DL. Long noncoding RNAs: functional surprises from the RNA world. Genes Dev. 2009;23(13):1494-504.

21. Bhan A, Soleimani M, Mandal SS. Long noncoding RNA and Cancer: a new paradigm. Cancer Res. 2017;77(15):3965-81.

22. Prensner JR, Chinnaiyan AM. The emergence of IncRNAs in cancer biology. Cancer Discov. 2011;1(5):391-407.

23. Kelemen E, Danis J, Goblos A, Bata-Csorgo Z, Szell M. Exosomal long noncoding RNAs as biomarkers in human diseases. Ejifcc. 2019;30(2):224-36.

24. Arun G, Diermeier SD, Spector DL. Therapeutic targeting of long noncoding RNAs in Cancer. Trends Mol Med. 2018;24(3):257-77.

25. Xu J, Li J, Zheng TH, Bai L, Liu ZJ. MicroRNAs in the occurrence and development of primary hepatocellular carcinoma. Adv Clin Exp Med. 2016; 25(5):971-5.

\section{Publisher's Note}

Springer Nature remains neutral with regard to jurisdictional claims in published maps and institutional affiliations.

Ready to submit your research? Choose BMC and benefit from:

- fast, convenient online submission

- thorough peer review by experienced researchers in your field

- rapid publication on acceptance

- support for research data, including large and complex data types

- gold Open Access which fosters wider collaboration and increased citations

- maximum visibility for your research: over $100 \mathrm{M}$ website views per year

At $\mathrm{BMC}$, research is always in progress.

Learn more biomedcentral.com/submissions 